Review Article

\title{
Pathogenesis of neonatal asphyxia
}

\author{
Rabindran ${ }^{1}$, Gedam DS ${ }^{2}$ \\ ${ }^{1}$ Dr. Rabindran, Consultant Neonatologist, Billroth Hospital, Chennai, ${ }^{2}$ Dr D Sharad Gedam, Professor, L N Medical \\ College, Bhopal, MP, India.
}

Address for correspondence: Dr Rabindran, E mail: rabindranindia@ yahoo.co.in

\begin{abstract}
Asphyxia results from compromised gas exchange. Pathogenesis of neonatal asphyxia involves energy crisis, lactic acidosis, excitotoxicity\& free radical injury. Initial poor oxygenation leads to hypoxemia with intact organ function.Later hypoxia develops with anaerobic metabolism followed by asphyxia with involvement of major organs. The changes during asphyxia depend on organ involvement \& its severity. Interference with cerebral blood flow secondary to systemic hypotension leads to failure of cerebral autoregulation thereby leading to ischemia, neuronal \&oligodendoglial damage via excitoxicity. Reduced oxygen supply leads to ineffective oxidative phosphorylation, anaerobic metabolism \& depletion of ATP reserves, accumulation of lactic acid \& hydrogen ions \& reduced cellular functions. ATP-dependent sodium-potassium pump fail leading to disruption of ion exchange across cell membrane leading to cell injury. Types of hypoxic brain damage include Haemorrhagic lesions, Destructive lesions involving white matter \& grey matter. Neuropathological patterns of injury include Selective neuronal necrosis, White matter lesions, Combined lesions \& Advanced lesions including Ulegyria, Multifocal cystic encephalopathy, Status marmaratus\&Unifocalpseudocyst. Brain ischemia, inflammation \& neuronal cell death are the 3 major steps in the pathogenesis of neural damage during asphyxia. Brain histology helps in timing of asphyxia which depend on aetiology \& stage of neurodevelopment.Reperfusion temporarily corrects this energy failure, however it may trigger delayed neuronal death or secondary damage due to brain swelling. Ischemia \& reperfusion induce both rapid \& delayed changes in gene expression. Asphyxia negatively affects integrity of the genome, triggering activation of sentinel proteins that maintain genome integrity.
\end{abstract}

Keywords: Asphyxia, Pathogenesis, Reperfusion Inury

\section{Introduction}

Asphyxia results from compromised placental or pulmonary gas exchange. This disorder can lead to hypoxia \& hypercarbia in the blood. Severe hypoxia results in anaerobic glycolysis \& lactic acid production first in the peripheral tissues (muscle $\&$ heart) \& then in the brain.Ischemia is both a cause \& result of hypoxia. Hypoxia \& acidosis can depress myocardial function, leading to hypotension \& ischemia. Ischemia can impair oxygen delivery, disrupt delivery of substrate \& removal of metabolic \& respiratory by-products (eg, lactic acid, carbon dioxide). Pathogenesis of neonatal asphyxia involves energy crisis, lactic acidosis, excitotoxicity\& free radical injury.

Etiopathogenesis of fetal hypoxia: Fetal hypoxia may

Manuscript received: $4^{\text {th }}$ April 2016

Reviewed: $15^{\text {th }}$ April 2016

Author Corrected: $26^{\text {th }}$ April 2016

Accepted for Publication: $10^{\text {th }}$ May 2016 be causedby (1) inadequate oxygenation of maternal blood (2) low maternal blood pressure (3) inadequate relaxation of uterus to permit placental filling (4) premature separation of placenta; (5) impedance of circulation of blood through umbilical cord (6) placental insufficiency.

Phases of injury during asphyxia: Initial poor oxygenation leads to hypoxemia where oxygen saturation in arterial blood falls without affecting organ function. Later hypoxia develops where there is reduced oxygen tension \& subsequent anaerobic metabolism involving peripheral tissues.

Finally asphyxia develops where hypoxia \& anaerobic metabolism involves organs like heart, brain \& adrenal glands, potentially leading to metabolic acidosis. Ischemia is oxygen deficiency due to hypoperfusion. 
Extent of organ damage: The changes during asphyxia depend on organ involvement \& its severity. Asphyxia impairs different organs (central nervous system 28\%, cardiovascular system 25\%, kidneys 50\%, lungs 23\%) [1]. Early congestion, fluid leak from increased capillary permeability \& endothelial cell swelling lead to coagulation necrosis. Macroscopic appearance of asphyxial lesions include congested internal organs, small hemorrhages over thymus, lungs \& heart (epicardialhemorrhage) along with engorgement of cerebral veins. Central nervous system lesions include Hypoxic-ischemic encephalopathy, infarction, intracranial hemorrhage, seizures, cerebral edema, hypotonia\& hypertonia; Cardiovascular features include Myocardial ischemia, poor contractility, cardiac stun, tricuspid insufficiency \& hypotension; Pulmonary symptoms include Pulmonary hypertension, pulmonary haemorrhage \& respiratory distress syndrome; Renal symptoms include Acute tubular or cortical necrosis, adrenal haemorrhage; Gastrointestinal morbidities include Perforation, ulceration with haemorrhage \& necrosis; Metabolic derangements include Inappropriate secretion of antidiuretic hormone, hyponatremia, hypoglycemia, hypocalcemia \& myoglobinuria; Integument involvement include Subcutaneous fat necrosis; Hematological symptoms include Disseminated intravascular coagulation. Asphyxia causes gestational age-specific neuropathology. Cortical neuronal necrosis \& parasagittal ischemic injury occur in term babies whereas Periventricular Leukomalacia, status marmoratus of basal ganglia \& intraventricular haemorrhage occur in preterm babies.Arteriolar vasodilatation induced by hypercapnia is due to disactivation of mitochondrial ATP-sensitive $\mathrm{K}+$ channels.

There is increased VEGF expression which leads to i) endothelial swelling; ii) endothelial exhaustion; iii) endothelial detachment; iv) loss of the endothelial barrier. At histology loss of endothelial barrier is associated with following lesion - Endothelial disfunction a. Diffuse intravascular coagulation (DIC), b. Edema of perivascular tissues, c. Loss of microvascular reactivity, d. Perivascular hemorrhages, e. Dysfunction of tneurovascular brain unit, followed by dysfunction of brain blood barrier, leading to perivascular edema\& neuronal cell death.

Mechanism of Cell Injury: Interference with cerebral blood flow secondary to systemic hypotension leads to failure of cerebral autoregulation thereby leading to ischemia, neuronal \&oligodendoglial damage via

\section{Review Article}

excitoxicity. Reduced oxygen supply leads to ineffective oxidative phosphorylation, anaerobic metabolism \& depletion of ATP reserves, accumulation of lactic acid \& hydrogen ions (i.e. acidosis) \& reduced cellular functions [2-4]. ATP-dependent sodiumpotassium pump fail leading to disruption of ion exchange across cell membrane leading to cell injury. In neurons intracellular accumulation of sodium, calcium \& water occur leading to cytotoxic edema, depolarization, release of excitatory neurotransmitters from axon terminals particularly glutamate. Increased intracellular calcium activates neuronal nitric oxide synthase which induces nitric oxide mediated free radical injury. Activation of phospholipases leads to fatty acids accumulation in cytoplasm which produce oxygen free radicals by mitochondrial peroxidation $[2,4]$. Mitochondrial membrane depolarisation occurs followed by increment of intracellular $\mathrm{Ca} 2+$ leading to apoptosis [5].

Hypoxic Encephalopathy:Neonatal hypoxic-ischemic encephalopathy is an acute, nonstatic encephalopathy caused by brain hypoxia \& ischemia during or closely associated with labour.

Types of asphyxial brain damage: Types of hypoxic brain damage include 1) Haemorrhagic lesions involving germinal matrix, ventricules, choroid plexus, cerebellum \&pial matter, 2) Destructive lesions involving white matter like leukomalacia involving periventricular, subcortical \&telencephalic areas, 3) Destructive lesions involving grey matter areas such as pontosubiculum, cerebral cortex, basal ganglia, thalamus \& brain stem [6].

\section{Neuropathological patterns of injury:}

I. Selective neuronal necrosis- occursin areas with high energy demands like 1) Cerebral cortical areas like Precentralgyrus, postcentralgyrus\&calcarine cortex, 2) Deep gray matter regions like thalamus \& basal ganglia, 3) areas in hippocampus like pontine nuclei \&subiculum. In severe asphyxia Global cerebral necrosis occurs involving cerebral cortex, brain stem, thalamus, spinal cord \& cerebellum.

II. White matter lesions- include Periventricular leukomalacia\&Cerebral white matter gliosis.

III. Combined grey \& white matter lesions include Parasagittal cerebral injury, bilateral necrosis of cerebral cortex \& subjacent white matter in the watershed areas, Focal \& multifocal infarcts. 
IV. Advanced lesions in late stages include 1) Ulegyria- which is distorted cerebral gyri in the parasagittal areas, 2) Multifocal cystic encephalopathywhich is sponge like brain with large septated cavities throughout cortex \& white matter of both hemispheres, 3) Status marmaratus - which is marbled appearance of striatum \&/or thalamus secondary to neuronal loss, astrogliosis\& excessive myelination, 4) Unifocalpseudocyst, cystic periventricular leukomalacia, white matter hypoplasia, porencephaly\&hydranencephaly or basket brain.

Pathologic changes of neural injury during asphyxia: Brain ischemia, inflammation \& neuronal cell death are the 3 major steps in the pathogenesis of neural damage during asphyxia.

Brain ischemia: ATP depletion leads to primary cellular energy failure $\&$ initiation of cascade reactions leading to cell death. Metabolic acidosis itself may cause neuronal injury \& death, particularly due to excessive release of glutamate, energy-requiring excitotoxic cascade \& neuronal degeneration [2]. Metabolic acidosis also cause hypotension resulting in ischemia [7,8], impairment of myocardial function resulting in reduced cerebral blood flow[9]. Subsequent reperfusion deteriorates brain metabolism further by increasing oxidative stress damage [2] through activation of xanthine oxidase, cyclooxygenase enzymes \& superoxide from mitochondria. Neuronal \& endothelial nitric oxide synthetase activation leads to increase in nitric oxide production. Ultimately secondary energy failure occurs due to mitochondrial dysfunction $[4,10]$.

Brain inflammation: Activation of local inflammatory cells in affected brain tissue \& recruitment of circulating immune cells [4,11] leads to brain inflammation. Local inflammation is produced by activated microglia [12] producing a damage-associated molecular pattern (DAMPs). Toll-like receptors (TLRs) in the microglial cells [13] sense the DAMPs [14]\& induce activation of major transcription factor associated with inflammatory response, i.e. NF- $\kappa \mathrm{B}$ (nuclear factor kappa-light-chain-enhancer of activated B cells) which leads to induction of several genes associated with innate immune response, including proinflammatory cytokines such as: Tumoral necrosis factor- $\alpha$ (TNF- $\alpha), \quad$ Interleukin-1 beta (IL-1 $\beta$ ), Interleukin-6 (IL-6), Interleukin-10 (IL-10), Interferon gamma (INF- $\gamma) \&$ proteases such as matrix metalloproteinases 3 \& 9 (MMP-3 \& MMP-9) [15,16].

\section{Review Article}

Neuronal cell death: Necrosis is passive, ATPindependent process characterized by cellular swelling, mitochondrial damage, chromatin condensation, cytotoxic edema, cell lysis, cytokine release \& activation of inflammatory reactions. Apoptosis is an active, ATP-dependent process of programmed cell death characterized by cell shrinkage, chromatin condensation, DNA fragmentation with no activation of inflammatory responses $[4,10]$. In asphyxia apoptotic cell death occurs often followed by ischemic necrotic cell death. Hypoxia mediated energy failure prevents effective completion of ATP-dependent apoptotic processes thereby leading to necrosis [17]. In reperfused areas cell death mainly consists of apoptosis [2,10]. Mild to moderate asphyxia causes apoptotic cell death whereas severe asphyxia leads to necrosis [4,10]. Excitotoxic cell injury mainly induces necrosis. Glutamate receptors which increase during hypoxia make fetal neurons more vulnerable to excitotoxicity $[2,17]$.

Cerebral regions with high degree of glutamate receptor expression like hippocampus, cerebral cortex \& deep nuclear structures \& therefore more vulnerable to asphyxia [17]. Among the neural cells, Neurons are most vulnerable, followed by oligodendrocytes \& astrocytes, whhereas microglia cells are less susceptible to hypoxia [2]. Grey matter is primarily involved in term infants \& white matter in preterms [10]. Watershed areas in periphery of cerebral vascular supply are most susceptible to ischemia [10]. Acute, near total asphyxia causes central pattern of focal neuronal injury, affecting mainly thalamus, basal ganglia \& brain stem nuclei with cortical sparing whereas prolonged, partial asphyxia lead to cerebral cortical injury in watershed areas \& in parasagittal regions with relative sparing of central grey matter. Multiple cell death mediators are activated by neonatal Hypoxic injury, including various members of the Bcl2, Bcl-2-associated X protein (BAX), Bcl-2-associated death promoter (BAD) [18,19] death receptor [20], \&caspases [21,22] protein families, correlating with increased apoptosis [22,23]. Markers of apoptosis (cleaved caspase-3) and necrosis (calpain-dependent fodrin breakdown product) can be expressed by damaged neurons [24]. Asphyxia also increases markers for autophagosoma (microtubule-associated protein 1 light chain 3-11) \& lysosomal activities (cathepsin D, acid phosphatase \& $\beta$-N-cetylhexosaminidase) in cortical \& hippocampal CA3-damaged neurons, suggesting an activation of autophagic flux may be 
Review Article

related to apoptosis observed in delayed neuronal death after severe asphyxia [25, 26].

Timing of asphyxial injury: Brain histology helps in timing of asphyxia which depend on aetiology \& stage of neurodevelopment [6,27]. Immunohistochemical analysis of neuronal expression of markers such as Tumour Necrosis Factor-alfa (TNF $\alpha$ ), Interleukins (IL$1 \beta$, IL-6), macrophage marker (CD68), Heat Shock Proteins (HSPs), $\beta$ Amyloid Precursor Protein ( $\beta$ APP), anti-T tryptophan Hydroxylase (anti-TrypH), Growth Associated Protein 43 (GAP43), Glial Fibrillar Acidic Protein (GFAP), Cyclooxygenase 2 (COX2), OxygenRegulated Protein 150 (ORP-150) also help in assessing chronology of asphyxia.

Channels of brain injury: Energy depletion during prolonged hypoxia results in neuronal depolarisation \& release of excitatory amino acids like glutamate \& aspartate into the extracellular space [13,28]. Glutamate activates ionotropic NMDA, AMPA/KA \& metabotropic receptors. AMPA/KA receptor activation increases sodium conductance, depolarising the membrane \& activating voltage-dependent calcium channels including NMDA receptor channel. Metabotropic receptors mGluR1-mGluR5, through second messengers, mobilise calcium from intracellular reservoirs to cytosolic compartment, activating proteases, lipases \&endonucleases, which later initiate a process of cell death [29,30]. Ligand-gated ion channels (including both N-methyl-d-aspartate [NMDA] \& nonNMDA receptor subtypes, ionotropic glutamate receptors, metabotropic glutamate receptors (mGluRs) mediate excitotoxicity [31,32]. Aqua-porin proteins like aquaporin-4 (AQP4) are involved in onset \& clearance of cerebral edema after asphyxia [33,34]. Activation of astrocytes, microglia \& macrophage mediate inflammation $[31,35]$ leading to increased expression of IL-1 $\beta$ \& complement components C1q \& C3d within hippocampus particularly in CA1. The increase in extracellular dopamine levels can result in alterations in the sensitivity of neurons to excitatory amino acids $[36,37]$. The neurotoxic effect of dopamine is due to an increase in production of free radicals during reoxygenation period $[38,39]$.

Reperfusion injury: Normal transition from fetal to newborn life is associated with an immediate decrease in cerebral blood flow velocity, followed by an increase above fetal level by 24 hours of life [40]. In asphyxiated infants this alteration in cerebral blood flow is disturbed. During compromised cerebral blood flow, deprivation of cerebral oxygen $\&$ glucose supply occurs which lead to ATP depletion. This energy failure leads to loss of $\mathrm{Na}+/ \mathrm{K}+-$ ATPase activity ultimately leading to cytotoxic edema [41,42]. Reperfusion temporarily corrects this energy failure, however it may trigger delayed neuronal death $[42,43]$ or secondary damage due to brain swelling. Two main sources of these metabolites are 1) oxidation of hypoxanthine to xanthine by xanthine oxidoreductase \& 2) neutrophils accumulating in ischemic \&reperfused tissue. In animal studies, resuscitation after ischemia leads to a period of hyperemia, followed by hypoperfusion $[41,44]$ due to endothelial injury \& swelling [45,46], granulocyte plugging of microvessels $[47,48]$ or intravascular clotting [49].

Gene alterations during asphyxia: Ischemia \& reperfusion induce both rapid \& delayed changes in gene expression. Transcription of several members of cfos \& c-junproto-oncogene families is increased in postischemic brain [50], heart [51] \& kidney [52]. Alterations in gene expression include phosphorylation of transcription factors c-jun \& ATF-2 by stressactivated protein kinases [53], altered binding of transcription factors, including AP-1 \& induction of cjun [53].

Sentinel proteins: Asphyxia negatively affects integrity of the genome, triggering activation of sentinel proteins that maintain genome integrity, such as poly (ADP-ribose) polymerases (PARPs) [54], X-Ray Cross Complementing Factor 1 (XRCC1), DNA ligase III $\alpha$ [55], DNA polymerase $\beta$ [56,57], Excision Repair Cross-Complementing Rodent Repair Group 2 (ERCC2) [58,59] \& DNA-dependent protein kinases [60].

Severe DNA damage is usually triggered by a massive degree of oxidative stress triggered by reactive oxygen species such as peroxynitrite, hydroxyl \& superoxide free radicals.

\section{Conclusion}

Understanding the pathogenesis \& neuropathology \& mechanisms of the cellular responses implicated in perinatal asphyxia \& the characterization of various organ injury might open new horizons for effective therapeutic strategiesfor neonatal asphyxia.An early diagnosistic evaluation of severity \& chronicity of asphyxial insult is of vital importance in planning the short \& long term management of asphyxiated newborns. 
Review Article

Funding: Nil, Conflict of interest: Nil

Permission from IRB: Yes

\section{References}

1. Bhatti, A.; Kumar, P. Systemic effects of perinatal asphyxia. Indian J. Pediatr.2014, 81, 231-233.

2. Lai MC, Yang SN. Perinatal hypoxic-ischemic encephalopathy .J Biomed Biotechnol. 2011; 2011: 609813. doi: 10.1155/2011/609813.

3. Ross MG. Labor and fetal heart rate decelerations: relation to fetal metabolic acidosis. ClinObstet Gynecol. 2011 Mar;54(1):74-82. doi: 10.1097/ GRF. 0b013e 31820a106d.

4. Perlman JM. Summary proceedings from the neurology group on hypoxic-ischeamic encephalopathy. Pediatrics. 2006; 117: S28-S33.

5. Robertson CMT, Perlman M. Follow-up of the term infant after hypoxic-ischemic encephalopathy. Paediatr Child Health.2006; 11: 278-282.

6. Squier W: Pathology of fetal and neonatal brain damage: identifying the timing. Acquired damage to the developing brain, Timing and causation. Edited by: Squier W. 2002, London: Arnold, 110-127.

7. Bennet L, Gunn AJ. The fetal heart rate response to hypoxia: insights from animal models. ClinPerinatol. 2009 Sep;36(3):655-72. doi: 10.1016/j.clp.2009.06.009.

8. Westgate JA, Wibbens B, Bennet L, Wassink G, Parer JT, Gunn AJ. The intrapartum deceleration in center stage: a physiologic approach to the interpretation of fetal heart rate changes in labor. Am J Obstet Gynecol. 2007; 197: 236.e1-236.e11.DOI: http://dx.doi.org/10.1016/j.ajog.2007.03.063

9. Shah PS, Perlman M. Time courses of intrapartum asphyxia: neonatal characteristics and outcomes. Am J Perinatal. 2009; 26: 39-44.

10. Distefano G, Pratico AD. Actualities on molecular pathogenesis and repairing process of cerebral damage in perinatal hypoxic-ischemic encephalopathy.Ital J Pediatr. 2010 Sep 16;36:63. doi: 10.1186/1824-728836-63.

11. Fathali N, Khatibi NH, Ostrowski RP, Zhang JH. The evolving landscape of neuroinflammation after neonatal hypoxia-ischemia. ActaNeurochir Suppl. 2011; 111:93-100. doi: 10.1007/978-3-7091-0693-8_15.

12. Giulian D, Vaca K. Inflammatory glia mediate delayed neuronal damage after ischemia in the central nervous system. Stroke. 1993;24:I84-I90. doi: 10.1161/ 01.STR.24.1.84.

13. Lehnardt S, Lehmann S, Kaul D, Tschimmel K, Hoffmann O, Cho S, et al. Toll-like receptor 2 mediates CNS injury in focal cerebral ischemia. J Neuroimmunol. 2007; 190: 28-33. doi: 10.1016/j. jneuroim.2007.07.023.

14. Hermoso MA, Cidlowski JA. Putting the brake on inflammatory responses: the role of glucocorticoids. IUBMB Life. 2003; 55:497-504. doi: 10.1080/ 15216540310001642072 .

15. Buller KM, Carty ML, Reinebrant HE, Wixey JA. Minocycline: a neuroprotective agent for hypoxicischemic brain injury in the neonate? J Neurosci Res. 2009 Feb 15;87(3):599-608. doi: 10.1002/jnr.21890.

16. Girard S, Kadhim H, Roy M, Lavoie K, Brochu ME, Larouche A, et al. Role of perinatal inflammation in cerebral palsy. Pediatr Neurol. 2009 Mar;40(3):16874. doi: 10.1016/j.pediatrneurol.2008.09.016.

17. Northington FJ, Chavez-Valdez R, Martin LJ.Neuronal cell death in neonatal hypoxiaischemia.Ann Neurol. 2011 May;69(5):743-58. doi: 10.1002/ana.22419.

18. Morales P, Fiedler JL, Andres S, Berrios C, Huaiquin P, Bustamante D, et al. Plasticity of hippocampus following perinatal asphyxia: effects on postnatal apoptosis and neurogenesis. J Neurosci Res. 2008 Sep;86(12):2650-62. doi: 10.1002/jnr.21715.

19. Ness JM, Harvey CA, Strasser A, Bouillet P, Klocke BJ, Roth KA. Selective involvement of BH3only Bcl-2 family members Bim and Bad in neonatal hypoxia-ischemia. Brain Res. 2006;1099:150-159. doi: 10.1016/j.brainres.2006.04.132.

20. Graham EM, Sheldon RA, Flock DL, Ferriero DM, Martin LJ, O'Riordan DP, et al. Neonatal mice lacking functional Fas death receptors are resistant to hypoxicischemic brain injury. Neurobiol Dis. 2004 Oct;17(1): 89-98.doi: 10.1016/j.nbd.2004.05.007. 
Review Article

21. Cheng Y, Black IB, DiCicco-Bloom E. Hippocampal granule neuron production and population size are regulated by levels of bFGF. Eur $J$ Neurosci. 2002;15:3-12. doi: 10.1046/j.0953-816x. 2001.01832.x.

22. Golan H, Huleihel M. The effect of prenatal hypoxia on brain development: short- and long-term consequences demonstrated in rodent models. Dev Sci. 2006;9(4):338-349.doi:10.1111/j.1467-7687. 2006. 00498.x.

23. Daval JL, Pourie G, Grojean S, Lievre V, Strazielle C, Blaise $\mathrm{S}$, et al. Neonatal hypoxia triggers transient apoptosis followed by neurogenesis in the rat CA1 hippocampus. Pediatric Research (2004) 55, 561-567; doi:10.1203/01.PDR.0000113771.51317.37

24. Blomgren K, Zhu C, Wang X, Karlsson JO, Leverin AL, Bahr BA, et al. Synergistic activation of caspase-3 by m-calpain after neonatal hypoxia-ischemia: a mechanism of "pathological apoptosis"? J Biol Chem. 2001;276:10191-10198. doi: 10.1074/jbc. M007807200.

25. Johnston MV, Fatemi A, Wilson MA, Northington F. Treatment advances in neonatal neuroprotection and neurointensive care. Lancet Neurol. 2011 Apr; 10(4):372-82. doi: 10.1016/S1474-4422(11)70016-3.

26. Ginet V, Puyal J, Clarke PG, Truttmann AC. Enhancement of autophagic flux after neonatal cerebral hypoxia-ischemia and its region-specific relationship to apoptotic mechanisms. Am J Pathol. 2009 Nov; 175(5): 1962-1974.doi: 10.2353/ajpath.2009.090463

27. Folkerth RD: The neuropathology of acquired preand perinatal brain injuries. SeminDiagnPathol. 2007, 24: 48-57.DOI:http://dx.doi.org/10.1053/j.semdp. 2007. 02.006

28. Herrera-Marschitz M, Morales P, Leyton L, Bustamante D, Klawitter V, Espina-Marchant P, et al. Perinatal asphyxia: current status and approaches towards neuroprotective strategies, with focus on sentinel proteins. Neurotox Res. 2011 May;19(4):60327. doi: 10.1007/s12640-010-9208-9.

29. Rothman SM, Olney JW. Glutamate and the pathophysiology of hypoxic-ischemic brain damage. Ann Neurol.1986;19:105-111.doi: 10.1002/ ana. 410190202.
30. Chen HL, Pistollato F, Hoeppner DJ, Ni HT, McKay RD, Panchision DM. Oxygen tension regulates survival and fate of mouse central nervous system precursors at multiple levels. Stem Cells. 2007 Sep;25(9):2291-301.

31.Kleman NW, Sun D, Cengiz P. Mechanisms underlying neonatal hypoxia ischemia. Open Drug Discovery J2010;2:129-3710.

32.Jantzie LL,Talos DM, Selip DB,et al.Developmental regulation of group I metabotropic glutamate receptors in the premature brain and their protective role in a rodent model of periventricular leukomalacia. Neuron Glia Biol2010;6:277-88

33.Ferrari DC, Nesic O, Perez-Polo JR.. Perspectives on neonatal hypoxia/ ischemia-induced edemaformation. Neurochem Res 2010;35:1957-65 .

34.Ferrari DC, Nesic OB, Perez-Polo JR.. Oxygen resuscitation does not ameliorate neonatal hypoxia/ ischemia-induced cerebral edema. J Neurosci Res 2010; 88:2056-65.

35. Squier W, Cowan FM. The value of autopsy in determining the cause of failure to respond to resuscitation at birth. SeminNeonatol 2004;9:331-45.

36. Knapp AG, Dowling JE. Dopamine enhances excitatory amino acid-gated conductances in cultured retinal horizontal cells. Nature. 1987;325:437-439. doi: $10.1038 / 325437 \mathrm{a} 0$.

37. Globus MY, Busto R, Dietrich WD, Martinez E, Valdes I, Ginsberg MD. Effect of ischemia on the in vivo release of striatal dopamine, glutamate, and gamma-aminobutyric acid studied by intracerebralmicrodialysis. J Neurochem. 1988; 51:1455 1464. doi: 10.1111/j.1471-4159.1988.tb01111.x.

38. Saugstad OD. Hypoxanthine as an indicator of hypoxia: its role in health and disease through free radical production. Pediatr Res. 1988;23:143-150. doi: 10.1203/00006450-198802000-00001.

39. Goplerud JM, Mishra OP, Delivoria-Papadopoulos M. Brain cell membrane dysfunction following acute asphyxia in newborn piglets. Biol Neonate. 1992; 61:33-41. doi: 10.1159/000243528. 
40.Connors G, Hunse C, Gagnon R, Richardson B, Han V, Rosenberg H 1992 Perinatal assessment of cerebral blood flow velocity wave forms in the human fetus and neonate. Pediatr Res 31:649-652.

41. Rosenberg AA, Murdaugh E, White CW 1989 The role of oxygen free radicals in post asphyxia cerebral hypoperfusion in newborn lambs. Pediatr Res 26:215219. Pediatr Res 26:215-219.

42.Siesjö BK 1992 Pathophysiology and treatment of focal cerebral ischemia. Part I. Pathophysiology.J Neurosurg. 1992 Aug;77(2):169-84.

43. Connolly ES, Winfree CJ, Springer TA, Naka Y, Liao H, Yan SD, Stern DM, Solomon RA, GutierrezRamos J-C, Pinsky DJ 1996 Cerebral protection in homozygous null ICAM-1 mice after middle cerebral artery occlusion. Role of neutrophil adhesion in the pathogenesis of stroke. J Clin Invest. 1996 Jan 1;97(1):209-16.

44. Palmer C 1995 Hypoxic-ischemic encephalopathy. Therapeutic approaches against microvascular injury, and role of neutrophils, PAF, and free radicals. ClinPerinatol 22:481-517.

45. Pluta R, Lossinsky AS, Wisniewski HM, Mossakowski MJ 1994 Early blood-brain barrier changes in the rat following transient complete cerebral ischemia induced by cardiac arrest. Brain Res 633:4152

46.Petito CK, Pulsinelli WA, Jacobson G, Plum F 1982 Edema and vascular permeability in cerebral ischemia: Comparison between ischemic neuronal damage and infarction. J NeuropatholExp Neurol. 1982 Jul;41(4): 423-36.

47. del Zoppo GJ, Schmid-Schönbein GW, Mori E, Copeland BR, Chang C-M 1991 Polymorphonuclear leukocytes occlude capillaries following middle cerebral artery occlusion and reperfusion in baboons. Stroke. 1991 Oct;22(10):1276-83.

48. Zhang R-L, Chopp M, Chen H, Garcia JH 1994 Temporal profile of ischemic tissue damage, neutrophil response, and vascular plugging following permanent and transient $(2 \mathrm{H})$ middle cerebral artery occlusion in the rat. J Neurol Sci. 1994 Aug;125(1):3-10.

\section{Review Article}

49. Thomas WS, Mori E, Copeland BR, Yu J-Q, Morrissey JH, del Zoppo GJ 1993 Tissue factor contributes to microvascular defects after focal cerebral ischemia. Stroke 24:847-854.

50. An G, Lin T-N, Liu J-S, Xue J-J, He Y-Y, Hsu CY 1993 Expression of c-fos and c-jun family genes after focal cerebral ischemia. Ann Neurol 33:457-464.

51. Brand T, Sharma HS, Fleischmann KE, Duncker DJ, McFalls EO, Verdouw PD, Schaper W 1992 Protooncogene expression in porcine myocardium subjected to ischemia and reperfusion. Circ Res 71:13511360.doi: 10.1161/01.RES.71.6.1351.

52. Witzgall R, Brown D, Schwarz C, Bonventre JV 1994 Localization of proliferating cell nuclear antigen, vimentin, c-Fos, and clusterin in the postischemic kidney. Evidence for a heterogenous genetic response among nephron segments, and a large pool of mitotically active and dedifferentiating cells.J Clin Invest. 1994 May;93(5):2175-88.

53. Pombo CM, Bonventre JV, Avruch J, Woodgett JR, Kyriakis JM, Force T 1994 The stress-activated protein kinases are major c-jun amino-terminal kinases activated by ischemia and reperfusion. $\mathrm{J}$ BiolChem 269(42) :26546-26551.

54. Alano CC, Ying W, Swanson RA. Poly(ADPribose) polymerase-1-mediated cell death in astrocytes requires $\mathrm{NAD}+$ depletion and mitochondrial permeability transition. J Biol Chem. 2004;279:1889518902. doi: 10.1074/jbc.M313329200.

55. Leppard JB, Dong Z, Mackey ZB, Tomkinson AE. Physical and functional interaction between DNA ligase IIIalpha and poly(ADP-Ribose) polymerase 1 in DNA single-strand break repair. Mol Cell Biol.2003; Aug 23(16):5919-5927. doi: 10.1128/MCB.23.16.59195927. 2003.

56. Mishra OP, Akhter W, Ashraf QM, DelivoriaPapadopoulos M. Hypoxia-induced modification of poly (ADP-ribose) polymerase and dna polymerase beta activity in cerebral cortical nuclei of newborn piglets: role of nitric oxide. Neuroscience. 2003;119(4):102332. doi: 10.1016/S0306-4522(03)00166-0.

57. Wilson SH. Mammalian base excision repair and DNA polymerase beta. Mutat Res. 1998;407:203-215. 
Review Article

58. Lubec B, Labudova O, Hoeger H, Kirchner L, Lubec G. Expression of transcription factors in the brain of rats with perinatal asphyxia. Biol Neonate 2002;81:266-278; DOI:10.1159/000056758.

59. Chiappe-Gutierrez M, Kitzmueller E, Labudova O, Fuerst G, Hoeger H, Hardmeier R, et al. mRNA levels of the hypoxia inducible factor (HIF-1) and DNA repair genes in perinatal asphyxia of the rat. Life Sci. 1998;63(13):1157-67.doi: $\quad$ 10.1016/S0024-3205(98) 00377-4.

60. Murcia G, Menissier de Murcia J. Poly(ADP-ribose) polymerase: a molecular nick-sensor. Trends Biochem Sci. 1994;19:172-176. doi: 10.1016/0968-0004(94) 90280-1.

\section{How to cite this article?}

Rabindran, Gedam DS. Pathogenesis of neonatal asphyxia. J Path Micro 2016;2(1):23-30.doi: 10.17511/jopm.2016.i01.05 